\title{
A risk and cost management analysis for changes during the construction phase of a project
}

S Schoonwinkel, C J Fourie, P D F Conradie

In civil construction projects, changes are inevitable, impacting projects in terms of cost, time and quality. It is nevertheless expected of project managers to effectively manage the impacts of project changes, and to complete the project within the project constraints, despite such changes. This article explores the impact of changes on a project by comparing the findings from a South African case study to the impact of changes found in literature. The article further investigates how consulting engineers in the Western Cape deal with changes in projects, and how cost risk management is performed during changes. The findings are startling and expose the shortage of necessary skills and competencies within project management. A fresh approach is required for project managers to deal effectively with project change.

\section{INTRODUCTION}

One of the primary ways in which value is generated in modern societies, is through projects that create physical assets, such as factories, commercial buildings, hospitals, schools and highways, which can then be exploited to social and economic ends. Most of these assets are created through construction projects, and as the size and complexity of these projects increase, a more intensive level of project management is required to successfully meet the expectations of time, cost and quality (Winch 2010).

However, managing a construction project is difficult in that all the relevant information is not always available at the initial stage of the project to plan and design the project accurately and make the best possible decisions. As information becomes available during the construction phase of the project, it can lead to various changes, which can in turn affect productivity, planned schedules, deadlines, work methodology, resource procurement and budget, all of which could result in the project objectives not being achieved. Design errors or variations, unforeseen site conditions and vagueness in the original scope are merely some of the reasons for change.

It is expected of a project manager to effectively manage the cost, time and risk impacts of all project changes, and complete the project within the project constraints regardless of any challenges. To manage projects more effectively, a fresh approach in project management is required. A project manager must understand the implications of changes and must manage these changes in such a way that all the project objectives are obtained within the time, budget and quality constraints.

Over and above the cost, time and risk consequences, changes can also affect stakeholder relationships and team morale. The uncertainties associated with change are often the result of iterative cycles or further changes due to unanticipated side-effects of the current change during the construction process (Lee et al 2005). It is thus imperative to understand change, the types of changes, its impact on the project, and how to analyse, manage and control it.

The aim of this article is therefore to determine the following two aspects about changes made to the works during the construction phase of a civil engineering project:

- What is the potential impact of project change?

- How are changes to the works currently managed in practice?

\section{METHODOLOGY}

In order to determine the impact of project change, the relevant literature was reviewed and a case study was done on a civil engineering construction project. The case study comprised the construction phase of a recently completed civil and structural construction project in South Africa, and the data for the case study was obtained from the consulting engineers who designed and managed the project. For the sake of confidentiality, all names of the stakeholders involved in the project have been omitted from this article.
TECHNICAL PAPER

\section{JOURNAL OF THE SOUTH AFRICAN INSTITUTION OF CIVIL ENGINEERING}

ISSN 1021-2019

Vol 58 No 4, December 2016, Pages 21-28, Paper 1375

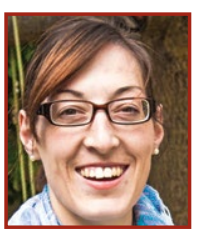

SUNÉ SCHOONWINKEL (Candidate Civil Engineer) graduated from Stellenbosch University, South Africa, in 2006 with a BEng degree in Civil Engineering. In January 2007 she joined Jeffares \& Green (now JG Afrika) in their Cape Town office. From 2010 to 2011 she took sabbatical leave to complete her MSc Eng degree in Engineering Management in the Department of Industrial Engineering at Stellenbosch University, focusing on the management of risk and cost during project management. In 2013 she left Jeffares and Green, and currently she is working for By Design, a consulting structural engineering firm in Stellenbosch.

Contact details:

By Design

Linton Street, Stellenbosch, 7600, South Africa

T:080 0128451

E: sune.schoonwinkel@gmail.com

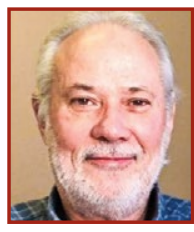

PROF CJ (NEELS) FOURIE (Pr Eng, MSAllE, MPMISA) graduated from the University of Pretoria in 1969 with a BSc degree in Industrial Engineering. He started his career at ISCOR, and then moved to Datsun (Nissan) and later Pretoria Metal Pressings (Armscor subsidiary) as a project manager, where he later became division head of Industrial Services. In 1987 he joined the Industrial Engineering Department at Stellenbosch University, where he obtained an MSc Eng degree in 1996 and a PhD in 2003. He became a professor in 2004 and served as the chair of the Industrial Engineering Department from 2005 to 2008. Since 2011 he has been chairing the university's PRASA Engineering Research Chair. His research focuses on lean manufacturing / management, project and programme management, maintenance management, risk management and statistical reliability engineering. He is the author of 15 peer-reviewed journal papers, three keynote papers and 41 papers delivered at international conferences. He has supervised 27 postgraduate students.

\section{Contact details:}

PRASA Engineering Research Chair

Faculty of Engineering

Stellenbosch University

P/Bag X1, Matieland, Stellenbosch, 7602, South Africa

T: +27218084237

E: cjf@sun.ac.za

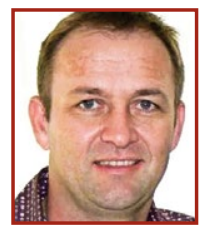

PIETER CONRADIE (Pr Eng) graduated from Stellenbosch University in 1994 with a BEng in Mechanical Engineering, and completed a post-graduate diploma in Industrial Engineering in 1995. He started his career at Spoornet, whereafter he moved to the manufacturing industry as production manager for various companies. He joined Stellenbosch University in 2011 as a research engineer and received his MEng in Engineering Management in 2015. He is an Associate Member of SAllE and a Member of the Institute of Asset Management. His research interests include physical asset management, reliability and maintenance management. He is the author of one international and one local conference paper, and one peer-reviewed journal paper.

Contact details:

Department of Industrial Engineering

Stellenbosch University

P/Bag X1, Matieland, Stellenbosch, 7602, South Africa

$\mathrm{T}:+27218084210$

E: pieterc@sun.ac.za

Keywords: project management, risk management, change management, civil projects, construction 
To be able to understand the project management environment and the state of change management in practice, the same case study was used and various interviews with project managers were done. The case study was analysed to understand how project finances were managed, the reasoning behind the particular management approach, its effectiveness, and its shortcomings.

To understand how the management of cost and risk, as a result of changes, are currently done in practice, 18 project managers were interviewed. These were mostly directors of consulting firms who are actively involved in the market place. The semistructured interviews consisted of a questionnaire to determine project managers' experience and modus operandi in managing the costs and risks of change. The results are reported in this article.

\section{IMPACT OF PROJECT CHANGE}

It is important that project managers understand the impact of change on a project. Project managers cannot make informed decisions regarding change without knowing what the effect of the change will be on the project. Changes that are mismanaged could prevent a project from achieving its objectives (Love et al 2002).

Figure 1 illustrates the influence that various factors can have on the project life cycle. It indicates the relationship of stakeholders' influence, risk and uncertainty against project time, as well as the cost of changes in relation to project change. This graph demonstrates that the impact of change becomes greater as the project progresses in time. The influence of project stakeholders, uncertainty and risk, reduces with time as the unknowns become less and the objectives are more clearly defined. Changes that happen during the construction phase of a project therefore have a greater cost impact on a project than changes that happen during the initial phases.

A study on the impact of project change conducted by Ibbs (1997) concluded the following:

- As the number of changes increase, costs will also increase.

- As change increases on a project, productivity decreases.

- Change that occurs during the construction phase of a project has a more disruptive impact on the project than change that occurs during the design phase of a project.

- A project that has a large number of changes would have less efficient implementation of those changes.

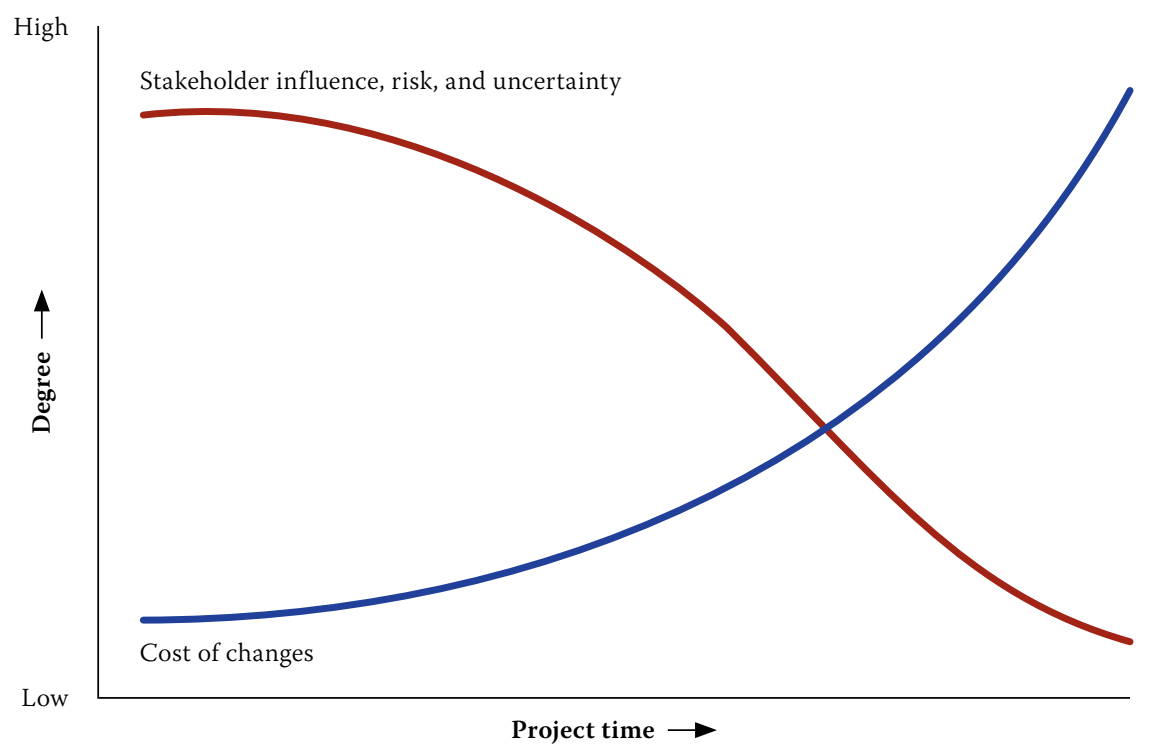

Figure 1 Impact of variables based on project time (Project Management Institute 2008)

Table 1 The impact of changes on a project

\begin{tabular}{|c|c|c|c|c|c|c|c|c|}
\hline \multirow{2}{*}{$\begin{array}{l}\text { Cause of } \\
\text { variation }\end{array}$} & \multicolumn{2}{|c|}{ No of events } & \multicolumn{2}{|c|}{$\begin{array}{l}\text { Non- } \\
\text { productive } \\
\text { time }\end{array}$} & \multicolumn{2}{|c|}{ Total cost (\$) } & \multirow{2}{*}{$\begin{array}{l}\text { Mean } \\
\text { cost per } \\
\text { event } \\
(\$)\end{array}$} & \multirow{2}{*}{$\begin{array}{c}\text { Percentage } \\
\text { of contract } \\
\text { value }\end{array}$} \\
\hline & $\#$ & $\begin{array}{l}\% \text { of } \\
\text { total }\end{array}$ & Days & $\begin{array}{l}\% \text { of } \\
\text { total }\end{array}$ & $\begin{array}{c}\text { Cost } \\
(\$)\end{array}$ & $\begin{array}{l}\% \text { of } \\
\text { total }\end{array}$ & & \\
\hline Client changes & 49 & 18 & 10 & 26 & 105620 & 13 & 2155 & 0.96 \\
\hline User changes & 132 & 48 & 14 & 36 & 235440 & 29 & 78 & 2.14 \\
\hline Design omissions & 83 & 30 & 13 & 33 & 265980 & 33 & 3205 & 2.43 \\
\hline Local authorities & 5 & 2 & 2 & 5 & 146080 & 18 & 29216 & 1.33 \\
\hline Extension of time & 6 & 2 & 0 & 0 & 53240 & 7 & 8873 & 0.49 \\
\hline Total & 275 & $(100)$ & 39 & $(100)$ & 806360 & $(100)$ & 43527 & 7.35 \\
\hline
\end{tabular}

Table 2 The impact of rework on a project

\begin{tabular}{|c|c|c|c|c|c|c|c|c|}
\hline \multirow{2}{*}{ Cause of variation } & \multicolumn{2}{|c|}{ No of events } & \multicolumn{2}{|c|}{$\begin{array}{l}\text { Non- } \\
\text { productive } \\
\text { time }\end{array}$} & \multicolumn{2}{|c|}{ Total cost $(\$)$} & \multirow{2}{*}{$\begin{array}{l}\text { Mean } \\
\text { cost per } \\
\text { event } \\
(\$)\end{array}$} & \multirow{2}{*}{$\begin{array}{c}\text { Percentage } \\
\text { of contract } \\
\text { value }\end{array}$} \\
\hline & $\#$ & $\begin{array}{l}\% \text { of } \\
\text { total }\end{array}$ & Days & $\begin{array}{l}\% \text { of } \\
\text { total }\end{array}$ & $\begin{array}{c}\text { Cost } \\
(\$)\end{array}$ & $\begin{array}{l}\% \text { of } \\
\text { total }\end{array}$ & & \\
\hline Design change & 65 & 30 & 20 & 29 & 182893 & 53 & 2814 & 1.67 \\
\hline Design error & 12 & 6 & 13 & 19 & 59233 & 17 & 4936 & 0.55 \\
\hline Design omission & 2 & 1 & 7 & 10 & 6837 & 2 & 3419 & 0.06 \\
\hline Construction change & 14 & 6 & 2 & 3 & 72979 & 21 & 5213 & 0.66 \\
\hline Construction error & 120 & 55 & 14 & 20 & 19514 & 6 & 163 & 0.17 \\
\hline Construction omission & 2 & 1 & 0 & 0 & 760 & 0 & 380 & 0.006 \\
\hline Construction damage & 3 & 1 & 14 & 20 & 3288 & 1 & 1096 & 0.03 \\
\hline Total & 218 & & 70 & & 345504 & & 1584 & 3.15 \\
\hline
\end{tabular}

\section{Case study by Love et al (2002)}

Love et al (2002) did a case study on a residential construction project (two six-storey residential apartment blocks, containing a total of 43 units) in order to better understand change and rework in construction project management.
Table 1 indicates that there were 275 items of change which resulted in 39 nonproductive days and a $7.35 \%$ increase in the cost of the works. Table 2 indicates that there were 218 items of rework which resulted in 70 non-productive days and a total additional cost of $\$ 345504.00$, which is $3.15 \%$ of the 
Table 3 Information of item changes to the project

\begin{tabular}{|c|c|}
\hline \multicolumn{2}{|l|}{ Item information } \\
\hline Number of original pay items in the tender SOQ & 753 \\
\hline Number of new pay items added to the SOQ & 445 \\
\hline Number of original pay items in the tender SOQ that were never claimed & 212 \\
\hline Total number of pay items that represent all the changes to the project & 657 \\
\hline Increase in rates claimed due to new rates added to SOQ & $59.1 \%$ \\
\hline Decrease in rates claimed due to omission of tender rates from SOQ & $28.2 \%$ \\
\hline
\end{tabular}

Table 4 Value of changes to the project

\begin{tabular}{|l|c|c|}
\hline \multicolumn{1}{|c|}{ Description } & $\begin{array}{c}\text { Value } \\
\text { (R) }\end{array}$ & $\begin{array}{c}\text { \% of tendered } \\
\text { project value }\end{array}$ \\
\hline Tendered value of project (excl VAT and contingencies) & 135660389 & - \\
\hline Cost of project at completion & 133150703 & $98.2 \%$ \\
\hline Value of new works added to project & 17741498 & $13.1 \%$ \\
\hline Extension of time cost & 1009330 & $0.7 \%$ \\
\hline Total of additional costs to project & 18750828 & $13.8 \%$ \\
\hline Value of pay items omitted from project & -17720274 & $-13.1 \%$ \\
\hline Value of quantity changes to tendered items in the SOQ & -3540239 & $-2.6 \%$ \\
\hline Total of omission costs to project & -21260514 & $-15.7 \%$ \\
\hline Total cost of changes to the project & -2509685 & $-1.8 \%$ \\
\hline
\end{tabular}

total contract value. The changes and rework of the project had a combined $10.5 \%$ cost impact on the project and resulted in 109 non-productive days.

Change could also result in rework. Construction is the physical manifestation of a design, and thus rework usually entails the demolition or modification of work already constructed. For this reason, rework is perceived to have a greater impact on construction performance than change. When project managers are under time or resource constraints, they would rather avoid rework by modifying the design and specifications. In the case study under review, the value spent on changes is more than double the amount spent on rework. It is thus clear that change may have a greater impact on the works than rework (Park \& Peña-Mora 2003).

The case study therefore made the following findings:

- Change can have a significant cost and time impact on a construction project.

- Change has a greater impact than rework.

\section{Case study conducted by the authors}

The authors also did a case study to determine the impact of project change. The project reviewed for the case study was the construction of a multi-million rand integrated industrial facility for a metropolitan municipality. The project was designed and managed by civil and structural consulting engineers in a joint venture with mechanical and electrical consulting engineers. The contract covered the construction of the structures, civil works and infrastructure, as well as the buildingrelated mechanical, electrical and electronic works. Separate contracts covered the provision of specialised mechanical and electrical infrastructure. This contract was based on the General Conditions of Contract (SAICE 2004), and the tendered civil and structural contract value was in the order of R160 million (including VAT and contingencies), with a construction period of 16 months.

For the purpose of the case study the researchers reviewed all the site memorandums (SMs), requests and quote rates (QRs) and variation orders (VOs) against all the new work and changes made to the project during the construction phase. Other available data (such as documentation, minutes of meetings, etc) was also perused for a better understanding of the project. The data was used to determine how many changes occurred on the project, how these were managed, and what the cost impact was.

For this project the main schedule of quantities (SOQ) had 753 original pay items. Each pay item of the SOQ has a tender quantity, rate and amount value (amount value is defined as the tendered quantity multiplied by the tendered rate). All the item amounts add up to the tendered value of the contract.

During construction of this project, 445 new pay items were added to the SOQ, and 212 pay items of the SOQ were never claimed and were thus omitted from the works. All these items were captured in the VOs. This data is reflected in Table 3.

Table 3 also indicates that the number of tendered SOQ pay items increased with a significant $59 \%$, and that $28.2 \%$ of the original pay items were never claimed during the construction period of the project. These values clearly indicate that there were a substantial number of changes made to the project.

In this specific case extensive design changes were made to the project, due to the impact of the design requirements from the mechanical and electrical plant contracts, which impacted the civil and structural works of the contract under revision. One main reason for such a large value of omissions on the project was the reduction in the clients' available budget for the works. This only became known after receiving the tenders, and therefore necessitated various changes and omissions to the initial design.

To determine the impact of changes to the project, the changes had to be quantified. The value of all the works added to the project; any extension of time or cost to the project, all omissions, as well as cost of variation between the tendered and claimed values of the scheduled work had to be determined. These costs could then be expressed as a percentage of the tendered contract value in order to determine the impact of the changes on the project, as can be seen in Table 4 .

As seen in Table 4, the value of additional costs to the project is $13.1 \%$ of the total contract value, which is significantly higher than the $10 \%$ contingency usually allowed for additional works. However, there was an equal reduction to costs of $13.1 \%$ due to work omissions. Of the R17 720274.96 saved due to omissions, R10 120000.00 (7.46\% of the tendered project value) was forced omissions due to a budget reduction by the client.

There was also a $2.6 \%$ saving on the project due to changes to the initial tendered quantities, resulting in an overall $1.8 \%$ decrease in the tendered value of the project.

The cost impact of changes can further be analysed by taking a look at the rate categories of new items added to the project, as given in Figure 2, and the total value of the items per category, as given in Figure 3.

The majority of items (89\% of the 445 new items of work) have a value of less than $0.05 \%$ of the contract's tendered value. They represent only $28 \%$ of the value of additional work added to the project, as shown in Figure 3 . Whereas only $1 \%$ of the additional items to the project have a value greater than $0.5 \%$ of the contract's tendered value, these changes amount to $30 \%$ of the total value 
of additional works. The 'medium high' and 'high' categories (as seen in Figure 2) amount to $5 \%$ of the number of additional items, but they represent more than $50 \%$ of the total value of the items added to the project. These two categories thus have the greatest impact on the finances of the project.

As stated in Table 3, there are 753 pay items in the original tender SOQ. Of these 753 items, 212 items (28.2\%) were omitted from the project, thus leaving 541 claimed items from the tender. The quantity variance of these claimed items will be broken up into further sub-categories. As can be seen in Table 5, 146 (19.4\%) of the claimed tender items show a $15 \%$ decrease in their tendered quantities, resulting in a saving to the project. The investigation shows that 138 claimed tender items (18.3\%) experienced more than $15 \%$ increase in the original quantities. Only 257 items (34.1\% of the total) have a quantity variance between $-15 \%$ and $15 \%$, which can be expected according to the industry standard. Of these 257 items, 177 items have no quantity variance. Thus only $23.5 \%$ of all tendered items were claimed without any variance in quantity or cost.

The contract allowed for all pay items to be re-measurable. The tender quantities listed are based on estimates done during the design phase of the project. However, when the design changes, the quantities might also change.

Table 6 indicates a significant cost implication for all tendered items with a decrease or increase to the quantities of more than $15 \%$. These changes to the item quantities amount to more than $10 \%$ of the tendered project value. It is thus clear that quantity changes of more than $15 \%$ can have a significant impact on the project.

Based on the data given above, the findings of the case study can be summarised as follows:

- Projects can have a significant number of changes.

- Similar to Love et al (2002), the authors found that the impact of changes on cost can be significant.

- Changes with a value greater than $0.1 \%$ of the total contract value have a huge impact on the finances of the project.

- Quantity changes of more than $15 \%$ have a significant cost impact on the project.

\section{CHANGE MANAGEMENT IN CURRENT PRACTICE}

During a construction project there may be quite a number of changes. Regardless of the size of the change, each alteration to the works has a cost, time, quality and risk

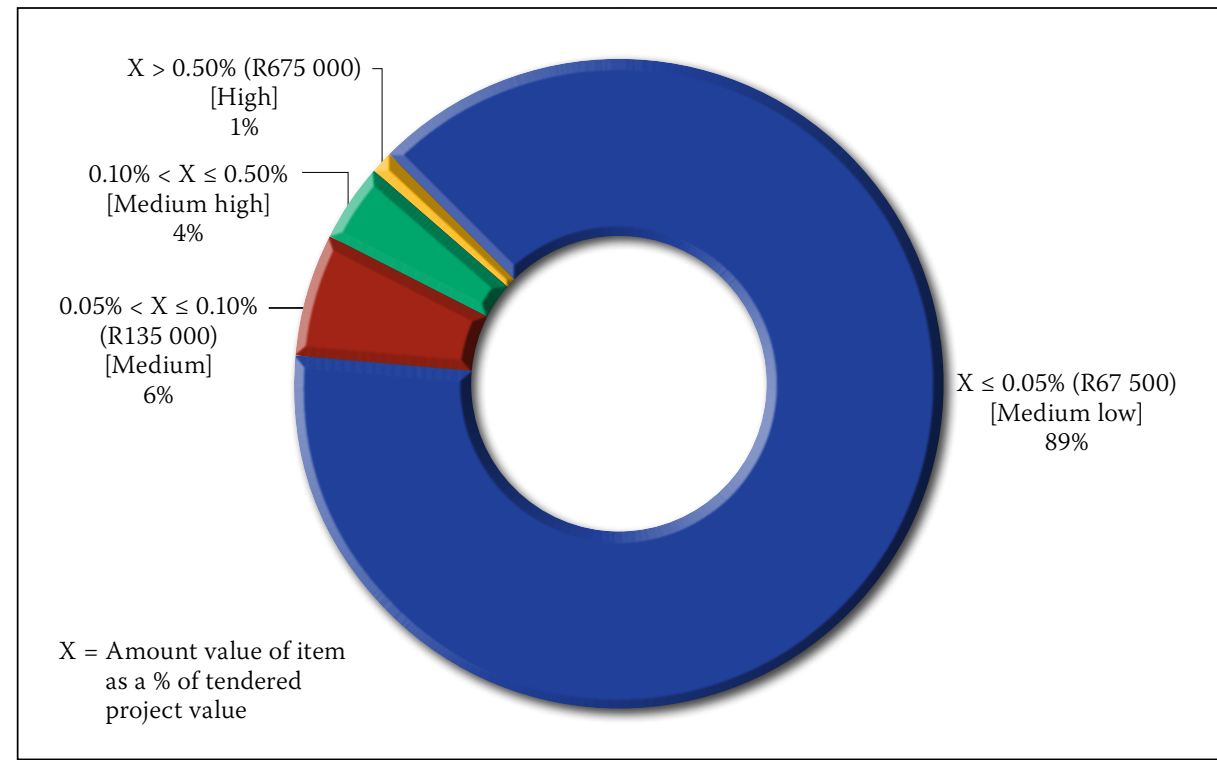

Figure 2 Rate categories of new items added to the project

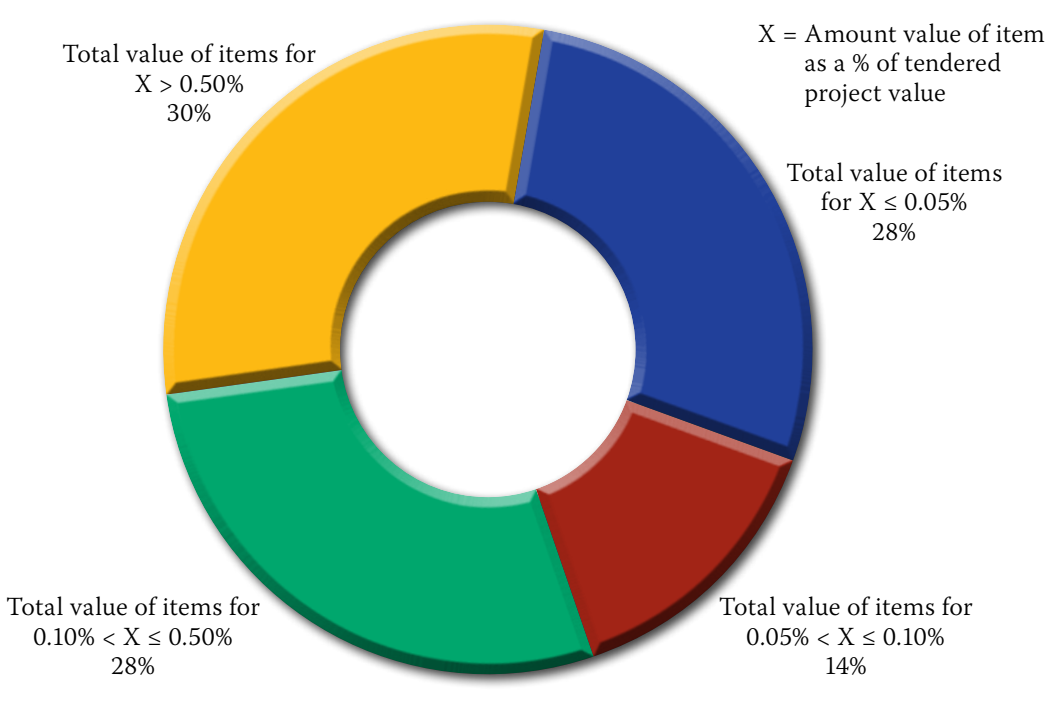

Figure 3 Total value of new items

Table 5 Quantity variance of items

\begin{tabular}{|l|c|}
\hline Quantity variance of items between the tender SOQ and the final claimed SOQ (represented by Y) \\
\hline Number of items in the tender SOQ & 753 \\
\hline Number of original pay items in the tender SOQ that were omitted & 212 \\
\hline Number of items in the tender SOQ that were used & 541 \\
\hline Number of items for which $\mathrm{Y} \leq-15 \%$ & 146 \\
\hline Number of items for which $-15 \%<\mathrm{Y} \leq 15 \%$ & 257 \\
\hline Number of items for which $-15 \%<\mathrm{Y}<0$ & 42 \\
\hline Number of items for which $0<\mathrm{Y} \leq 15 \%$ & 38 \\
\hline Number of items for which $\mathrm{Y}=0$ & 177 \\
\hline Number of items for which $\mathrm{Y}>15 \%$ & 138 \\
\hline
\end{tabular}

implication. Due to tight time constraints on most projects, every change requires quick, robust decision-making, so as to not delay the project, which therefore results in changes not being comprehensively evaluated. Based on feedback from project managers, decisions are often made on intuition or experience, sometimes without an assessment of the risks involved or the influence on the cost of the project, and often without applying well-known project management techniques. Mainly because of 
Table 6 Cost implication of quantity variance of items

\begin{tabular}{|l|c|c|}
\hline \multicolumn{1}{|c|}{ Cost implication of quantity variance $(\mathrm{Y})$} & $\begin{array}{c}\text { Value } \\
\text { (R) }\end{array}$ & $\begin{array}{c}\text { \% of tendered } \\
\text { project value }\end{array}$ \\
\hline Value of quantity changes $(\mathrm{Y} \leq-15 \%)$ & -20340820 & $-15.0 \%$ \\
\hline Value of quantity changes $(-15 \%<\mathrm{Y}<0)$ & -1408678 & $-1.0 \%$ \\
\hline Value of quantity changes $(0<\mathrm{Y} \leq 15 \%)$ & 1278587 & $0.9 \%$ \\
\hline Value of quantity changes $(\mathrm{Y}>15 \%)$ & 16930671 & $12.5 \%$ \\
\hline Total value of quantity changes & -3540239 & $-2.6 \%$ \\
\hline
\end{tabular}

\section{Table 7 Cost reporting of new items}

\begin{tabular}{|l|c|c|c|c|}
\hline \multicolumn{1}{|c|}{ Description } & $\begin{array}{c}\text { Number } \\
\text { of items }\end{array}$ & $\begin{array}{c}\text { As \% of } \\
\text { new items }\end{array}$ & $\begin{array}{c}\text { Value } \\
\text { (R) }\end{array}$ & $\begin{array}{c}\text { As \% of } \\
\text { new works }\end{array}$ \\
\hline New items & 445 & $100.0 \%$ & 17741498 & $100.0 \%$ \\
\hline Items that have an SM & 136 & $30.6 \%$ & 6465132 & $36.4 \%$ \\
\hline Items with no SM & 309 & $69.4 \%$ & 11276366 & $63.6 \%$ \\
\hline Items that have a CQ & 140 & $31.5 \%$ & 12155951 & $68.5 \%$ \\
\hline Items with no CQ & 305 & $68.5 \%$ & 5585547 & $31.5 \%$ \\
\hline Items that have either an SM or a CQ & 174 & $39.1 \%$ & 8814397 & $49.7 \%$ \\
\hline Items that have both an SM and a CQ & 51 & $11.5 \%$ & 4.903343 & $27.6 \%$ \\
\hline Items that have neither an SM nor a CQ & 220 & $49.4 \%$ & 4023758 & $22.7 \%$ \\
\hline
\end{tabular}

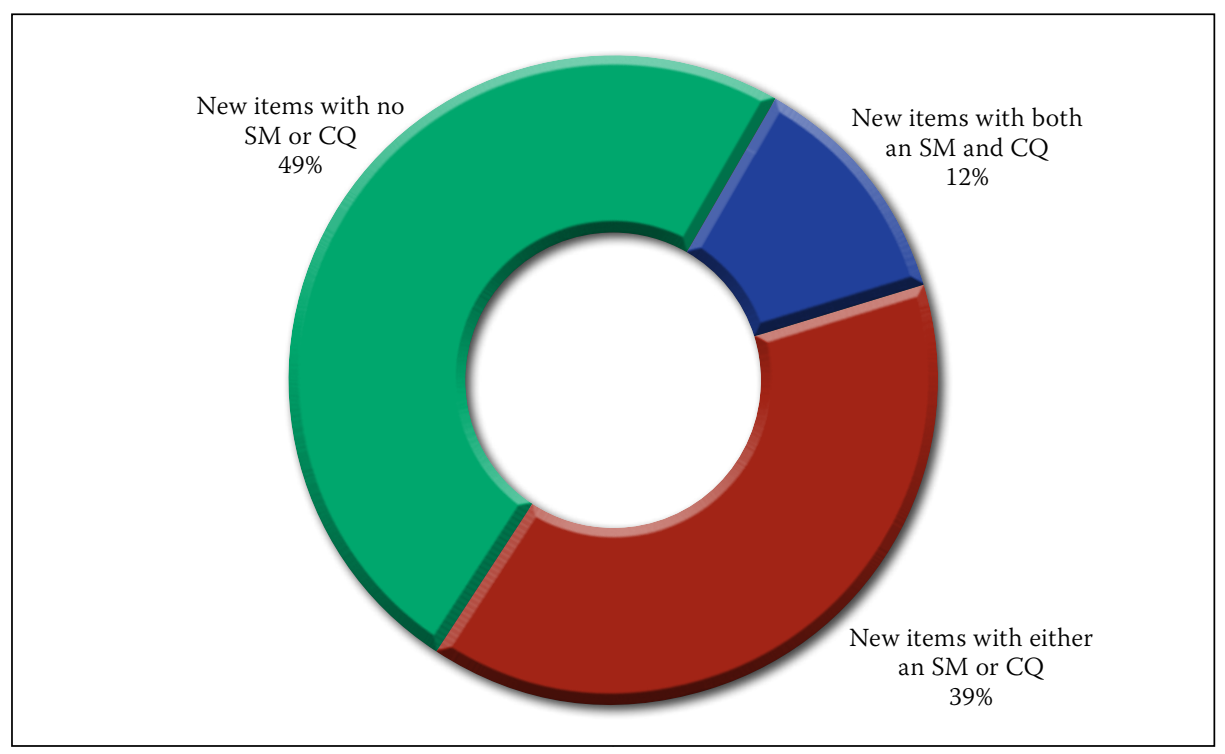

Figure 4 Cost reporting of new items

time constraints (Akintoye \& MacLeod 1997) project managers use contingencies and construction buffers as the only mechanism for dealing with unexpected change.

\section{Change management practices based on the case study}

To determine how the changes were evaluated and managed in the case study, the paperwork for all the changes was assessed. When a change is made to the project, it is recorded by the engineer in an SM, which gives a clear description of the change as well as the cost implication thereof (if available). The SM therefore serves as the record of the change and its implications, and is seen as an important document to the engineer. If the change involves work where no rate is specified in the tender SOQ, the engineer requests a quote for it in the SM. The contractor will then be required to supply the engineer with a contractor's quote (CQ) for the works, and the $C Q$ is then reviewed by the engineer to determine if it is fair and reasonable. These two references (SM and $\mathrm{CQ}$ ) are important for managing new items.

Table 7 summarises the project costs for new items. Of the 445 new items added to the SOQ, 174 items (39\%) were documented either in an engineer's SM or a CQ, 51 (12\%) items had both references, and 220 items (49\%) had no paper-based record at all (refer to Figure 4).

Table 7 indicates that for $68.5 \%$ of the new items added to the SOQ, there is no record of any quote or information received for the works from the contractor and no indication of any form of review. These items amount to $31 \%$ of the value of all new works added to the project. These rates are added to the SOQ without any formal evaluation of its fairness towards the client or the impact on the project budget. It also implies that no cost, time or quality analyses were made of the changes, and it can furthermore be assumed that no risk analysis was done for these changes.

Table 7 also indicates that SMs were issued for only $30.6 \%$ of the new works, and thus the remaining $69.4 \%$ of the items (representing $63.6 \%$ of the value of the works) must have been initiated by another means, which is in contradiction of the project plan. It can therefore safely be assumed that the changes that necessitated these rates were not properly reviewed before the contractor was instructed to do the works, nor were alternative options investigated. The contractor was also not given any written information, instructions or specifications on the changes.

However, it must be noted that the contractor's certificate was evaluated each month, and no rate could be added without the knowledge of the engineer. All items of change were also recorded in the VOs submitted to the client, compiled once a month in line with the monthly payment certificate (MPC). Even though the rates were not assessed in a formal, paper-based manner, they would have been acknowledged and reviewed at each MPC review. Certificate reviews consisted of detailed comparison of the changes between the quantities claimed in the current and the previous months, in order to assess the accuracy of the claim. However, the review only examines items of work claimed in the certificate which have commenced. This process would therefore have identified any new works added to the certificate, after their initiation, which is a reactive method and not the ideal way in which to manage cost changes.

The following concerns are raised for this case study:

- The method of change management is questionable.

- Not all changes are recorded in an acceptable manner.

\section{Change management practices based on interviews}

To examine how change management is currently being applied in practice, the 
researchers also interviewed 18 project managers, of whom more than two thirds are directors of active firms in the market place. They were asked questions regarding their experience in project management, and more specifically, the cost and risk management of changes. The demographics of the group are illustrated in Figure 5.

\section{How are changes managed in general by engineers?}

Interviewees were requested to answer various questions with regard to their experience of the management of changes based on the company procedure. The results are shown in Figure 6. It is evident that changes are predominantly managed in two ways through the requirements of the ISO 9000 certified quality management system (QMS), and a paper-based exercise of issuing SMs, VOs, QRs and MPCs (both these methods were stated by $50 \%$ of the interviewees). This substantiates the finding of the case study, which also found that changes are managed through the documenting and reviewing of SMs, VOs, QRs and MPCs. The results also indicate that, though there is a methodology or procedure in place, $33 \%$ of those interviewed admitted to not always following the set procedure prescribed by company protocol.

\section{How is the cost of changes managed?}

From the research it was found that not all changes are recorded in the appropriate manner, and that the cost and risk management of changes in most cases were inadequate. The participants generally regarded the following as methods by which they manage the cost of changes of new works:

- By doing a cost estimate of the proposed works.

- By asking for rates from the contractor and then assessing if the QRs are fair and reasonable.

- By determining the effect of the work on the project budget and contingencies.

- By determining if there are any other cost implications of the works, such as life cycle or time-related costs.

The results are shown in Figure 7, where only $33 \%$ of all participants determined the cost impact of the additional works on the overall project. The general opinion was that an initial cost estimate of the works is done and then the required rates are requested from the contractor. If the rate is found to be acceptable and within the allowed contingencies, it is added to the project. Quoting one of the participants: "You seldom go out to tender with a complete design, so you know there is going to be additional work, but you

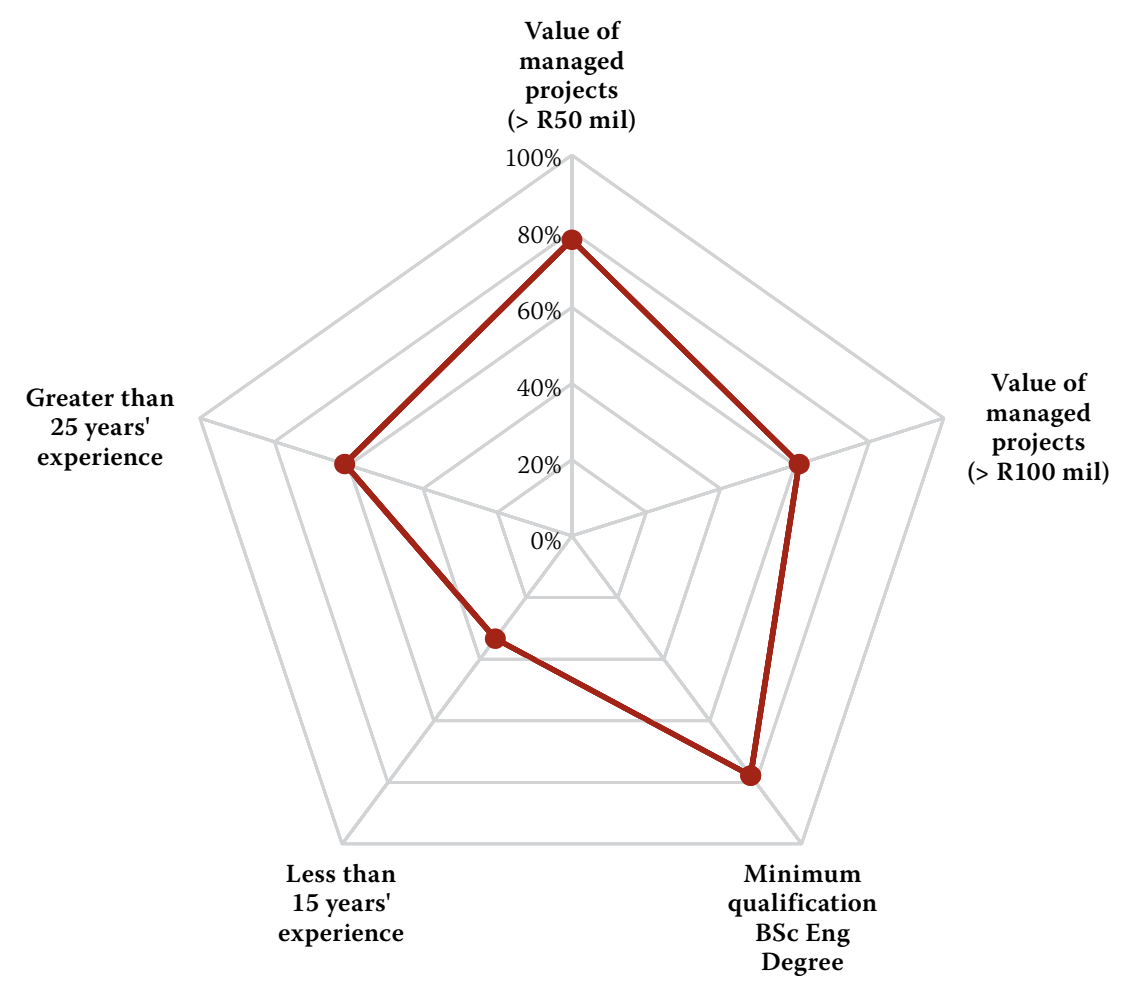

Figure 5 Demographic of interviewees

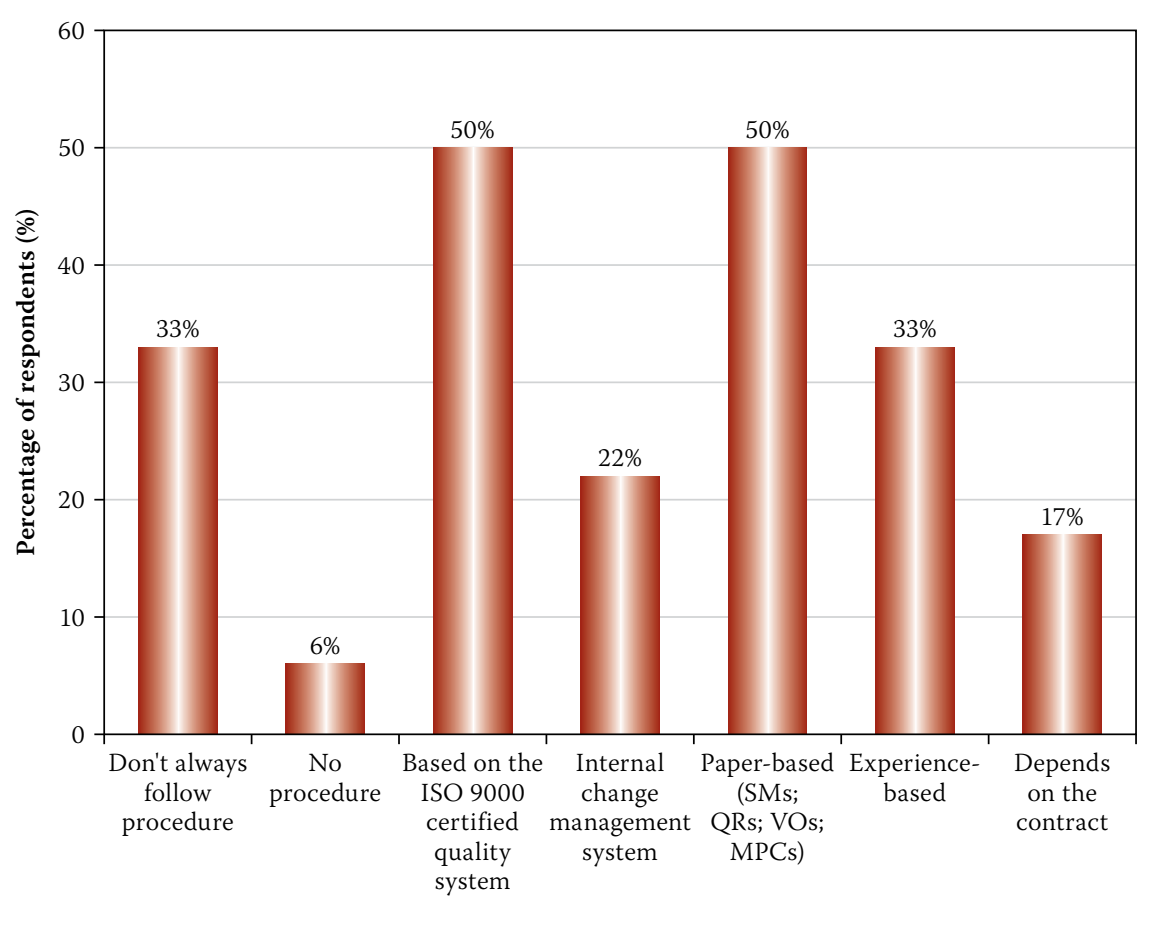

Figure 6 Methods of change management

don't know how much of your contingencies you are going to use."

The interviewees were then questioned on the process followed to determine how reasonable a rate was on a CQ for new works. The following main methods were identified:

- By comparing the given rate to known rates from similar projects.

- By comparing the given rate to relevant rates from the project's SOQ.
- By requesting that the contractor provides a breakdown of the QR.

- By acquiring supplier quotes for comparison to the QR.

- By judging the reasonableness of the rate based on experience.

Refer to Figure 8 for the results of the study. A rate breakdown, or the comparison of rates against those from similar projects or the existing SOQ, are similar methods to those identified by the case study and were thus expected. 


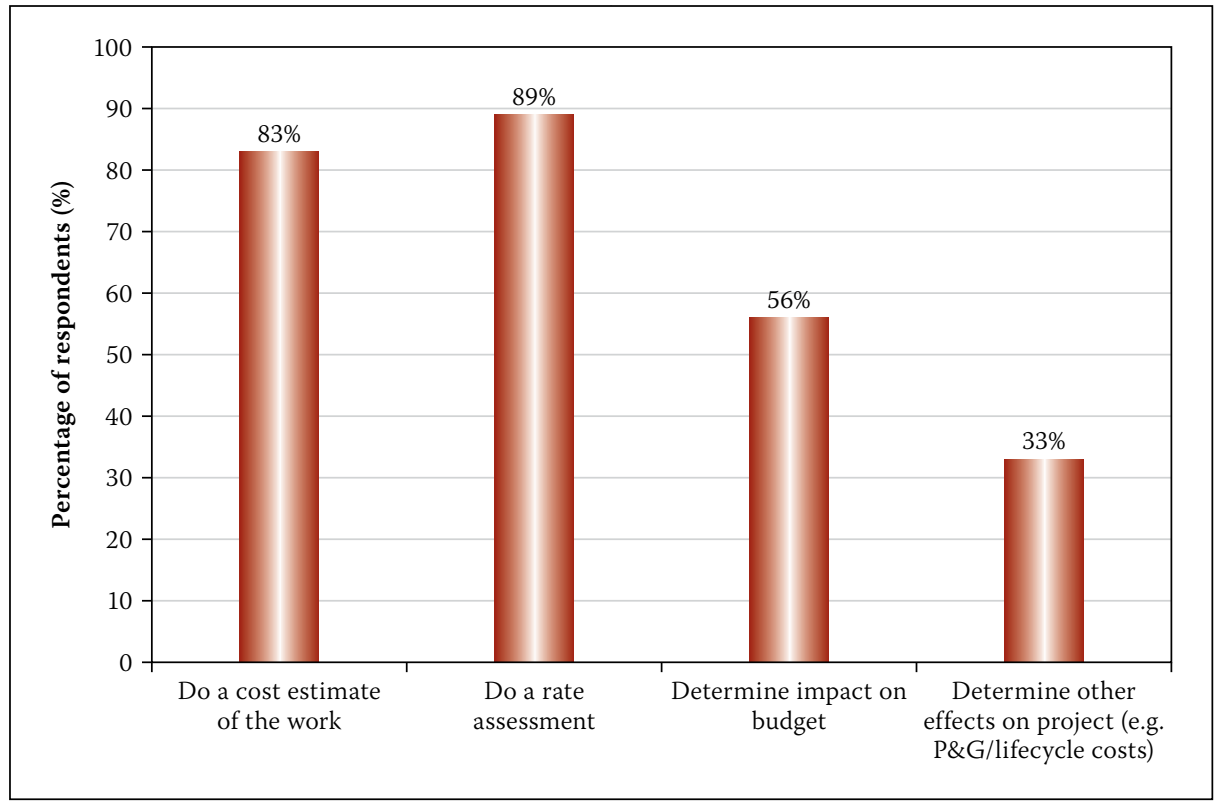

Figure 7 Methods of cost management

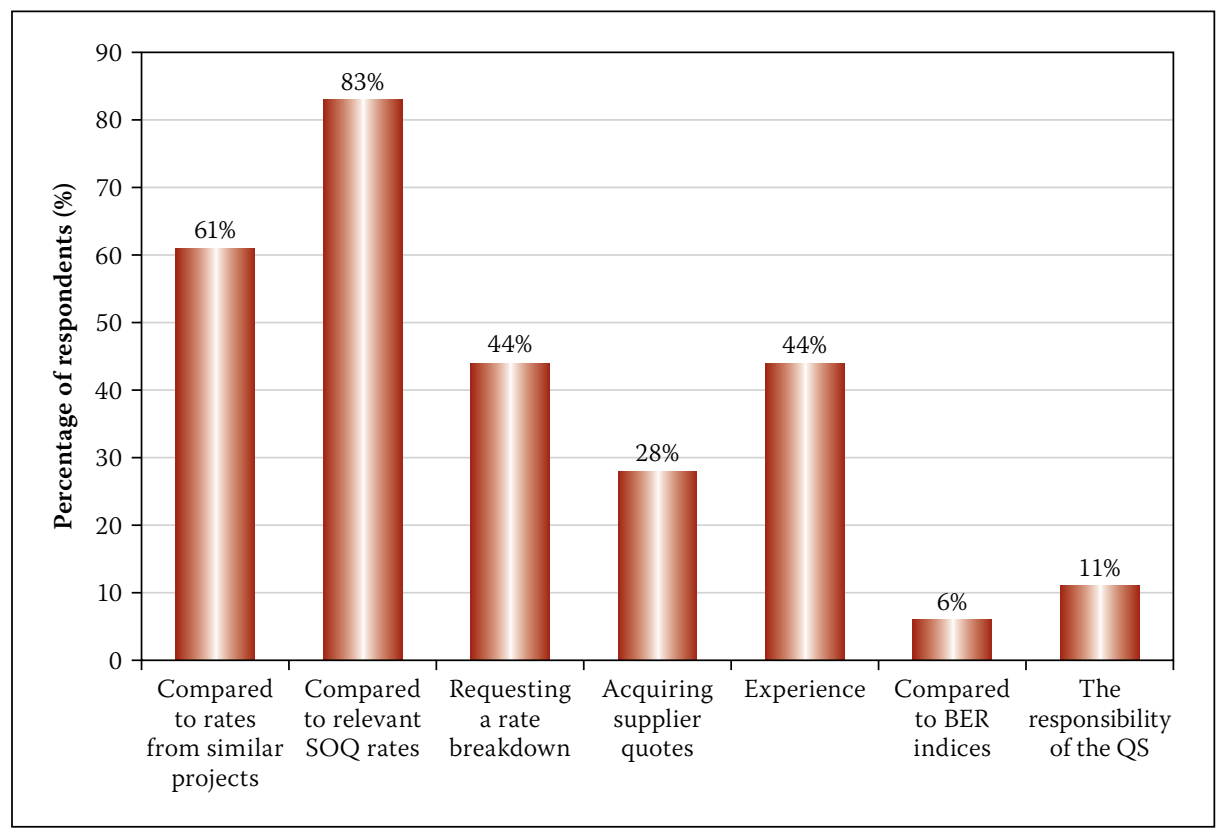

Figure 8 Methods how new rates are assessed

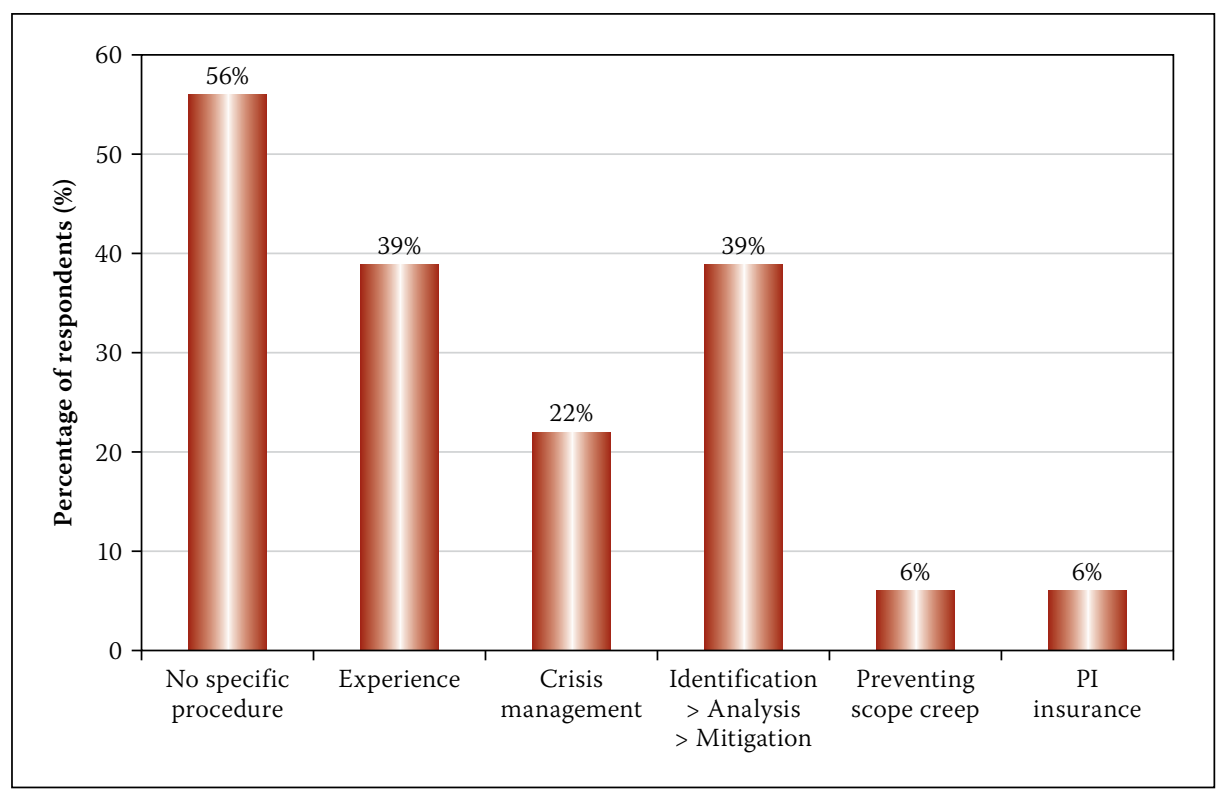

Figure 9 Methods of risk management
How are the risks of the

changes managed?

Risk management is a theoretical five-step process of planning, identification, assessment, determining the response, and monitoring and controlling the risks. However, when the project managers were asked how they manage risks, only $39 \%$ of interviewees followed this process, with more than 50\% following no specific procedure. Project managers manage risks using the following methods (refer to Figure 9):

- Experience

- Crisis management

- Identification, analysis and mitigation

- Preventing scope creep

- Professional insurance.

One of the respondents replied:

"Approximately $50 \%$ of our time is taken to manage things that go wrong, because everything is such a rush and we don't do our planning properly. That goes for us as engineers, architects and contractors. You have to keep correcting things and direct them in the right way."

This indicates that the risks pertinent to civil projects are not properly identified and managed, and most project managers do not follow the theoretical risk management process, rather relying on their experience and crisis management abilities.

\section{What are the current difficulties with} cost and risk management of changes? Most participants commented on the time constraints of cost management. When changes are requested, it often involves design changes which must be implemented as soon as possible, and thus the change management process delays the work. Therefore the cost management has to be fast and effective so that works are not delayed in the process.

A general finding was that for some participants, cost management merely revolved around ensuring that the budget is not overspent and that there is enough money in the contingency budget for the works. They also regard cost management as the assurance that the rate is reasonable according to the engineer's judgement. The overall effect of the works on the project, its indirect costs (such as maintenance), and time-related preliminary and general costs are rarely considered.

Time constraints were found to be the biggest obstacle for not applying standard risk management principles in practice. The two other major obstacles were knowledge and the practicality of risk management. When asked about the biggest stumbling block for performing risk management, an interviewee replied: "Time, and the lack of understanding 
in the project team that there is value in doing risk management. There is never time to do it, but always time to do it twice."

\section{SUMMARY OF FINDINGS}

This article investigated the impact that changes can have on a project, as well as the current state of change management of construction projects in practice. This was done by conducting a case study and various interviews with project managers. The key findings of the case study and various interviews with project managers, regarding the impact of changes on the project, can be summarised as follows:

- Change can have a significant cost and time impact on a construction project.

- Change has a greater impact than rework.

- Projects can have a significant number of changes.

- The bigger the changes, the greater the impact on the project.

- Changes with a value of more than $0.1 \%$ of the total contract value have a big financial impact on the cost of the project.

- Items with a quantity change of more than $15 \%$ have a significant cost impact on the project.

Based on the case studies and interviews conducted, current change management practices can be summarised as follows:

- Project managers are not managing changes appropriately.

- Changes are not recorded systematically.

- Project managers do not have a formal way in which they assess the cost, time and risk impact of a change.

- Changes are mainly managed based on the ISO 9000 certified QMS and a paperbased exercise.

- Project managers make extensive use of their experience and engineering judgement for managing the cost of changes.

- Other methods of cost management include:
- Doing a cost estimate of the proposed works.

- Requesting rates from the contractor and assessing their reasonableness.

- Determining the effect of the work on the project budget and contingencies.

- Determining the indirect cost implications, such as life cycle or time-related costs.

- More than $50 \%$ of participants do not follow a specific risk assessment procedure.

- Time, knowledge and practicality are hindering the application of standard risk management principles.

Most companies seem to have a QMS in place, but the practical application of that process is not clear. Changes to projects are captured through a paper-based exercise of SMs, QRs, VOs and MPCs. Neither the interviews, nor the findings of the case study indicated any current use of a formal change impact review methodology.

Most project managers do not follow the theoretical risk management process of planning, identification, analysis and mitigation. Time constraints were found to be the biggest reason why project managers do not apply generally accepted cost and risk management practices. They therefore follow no specific procedure and rely on their crisis management abilities.

\section{CONCLUSIONS}

The aim of the article was to determine the impact of changes made to the works during the construction phase of a civil construction project, and three main conclusions were made:

1. Changes can have a significant cost and time impact on a construction project, and changes have a greater impact than rework.

2. The current method of change management is not adequate, as not all changes are recorded in the appropriate manner, and risk management is seldom done.
3. Time, knowledge and practicality are factors hindering the application of standard risk cost and risk management principles. The results are disturbing, given the magnitude of the projects discussed in this study, and the possible implications of changes. The results expose project managers' and engineers' lack of critical skills and competencies, aspects which are prerequisites for the successful execution of a project in terms of time, quality and cost. It is therefore recommended that project managers and engineers are carefully selected, not only based on experience, but also based on the necessary skills and competencies.

\section{REFERENCES}

Akintoye, A S \& MacLeod, M J 1997. Risk analysis and management in construction. International Journal of Project Management, 15(1): 31-38.

Ibbs, C W 1997. Quantitative impacts of project change: size issues. Journal of Construction Engineering and Management, 123(3): 308-311.

Lee, S, Peña-Mora, F \& Park, M 2005. Quality and change management model for large scale concurrent design and construction projects. Journal of Construction Engineering and Management, 131(8): 890-902.

Love, P E D, Holt, G D, Shen, L Y, Li, H \& Irani, Z 2002. Using systems dynamics to better understand change and rework in construction project management systems. International Journal of Project Management, 20(6): 425-436.

Park, M \& Peña-Mora, F 2003. Dynamic change management for construction: introducing the change cycle into model-based project management. System Dynamics Review, 19(3): 213-242.

Project Management Institute 2008. A Guide to the Project Management Body of Knowledge. ANSI/PMI 99-001-2008, Philadelphia, PA: Project Management Institute.

SAICE (South African Institution of Civil Engineering) 2004. General Conditions of Contract for Construction Works, 1st ed. Midrand: SAICE.

Winch, G M 2010. Managing Construction Projects, 2nd ed. Oxford: Wiley-Blackwell. 